\title{
APPLICATION OF GIS IN THE TOURISM - DESIGNING A FRAME WORK FOR KERALA TOURISM
}

\section{Venugopal C $\mathrm{K}^{*}$}

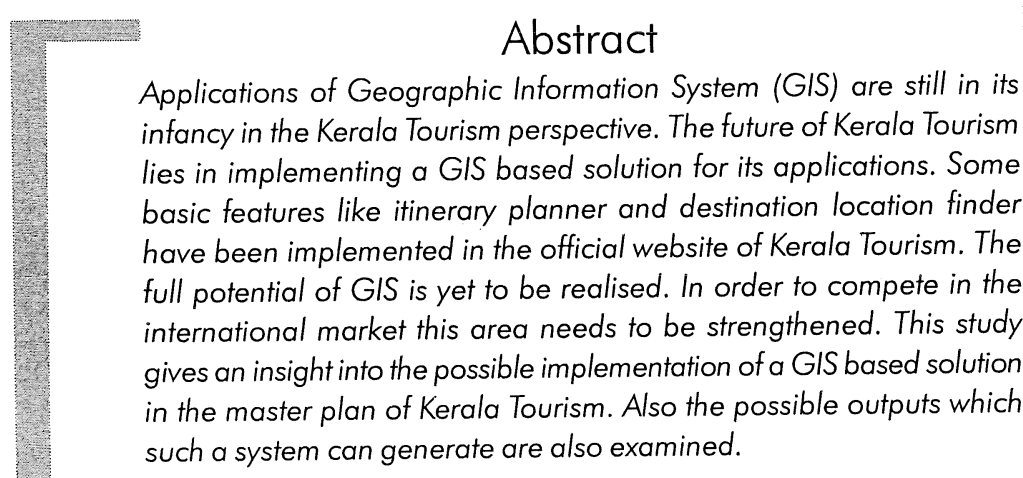

\section{Introduction}

Located in Southern India, Kerala, better known as God's own country is a state blessed with a plethora of natural resources and attractions. Kerala Tourism has

* Department of IT and languages, Kerala Institute of Tourism and Travel Studies (KITTS), Trivandrum, Kerala. 
over the last decade, gone about establishing itself in the global scenario with aplomb. To keep up with competition and to consolidate its position, a lot has to be planned and done. With Information Technology advancing by leaps and bounds, Tourism has been one of the chief beneficiaries. A model based on GIS for developing a platform where various applications can interact with each other holds the key to future development.

GIS uses cartography along with computerized location based services to cater to the needs of the user. Kerala occupies $1.25 \%$ of the total area of the country, India. Even though this may seem a small unit, due to the considerable diversity of Tourism resources, GIS offers immense scope for future development and access to information. Tourism is a spatial phenomenon and is ideally suited to be incorporated using a GIS. Since various types of spatial, statistical and network analysis are required on the data collected, GIS is a perféct solution provider in this area.

GIS is used to display and analyze spatial data which are linked to databases. This connection between spatial data and databases is the driving force behind the working of a GIS. Maps can be drawn from the databases and data can be referenced from the maps. When the database is updated, the associated map also gets updated. GIS database include a wide variety of information including geographic, social, political, environmental and demographic data. The figure shown below is a small example of the different layers of information that can be viewed and analysed with a GIS.

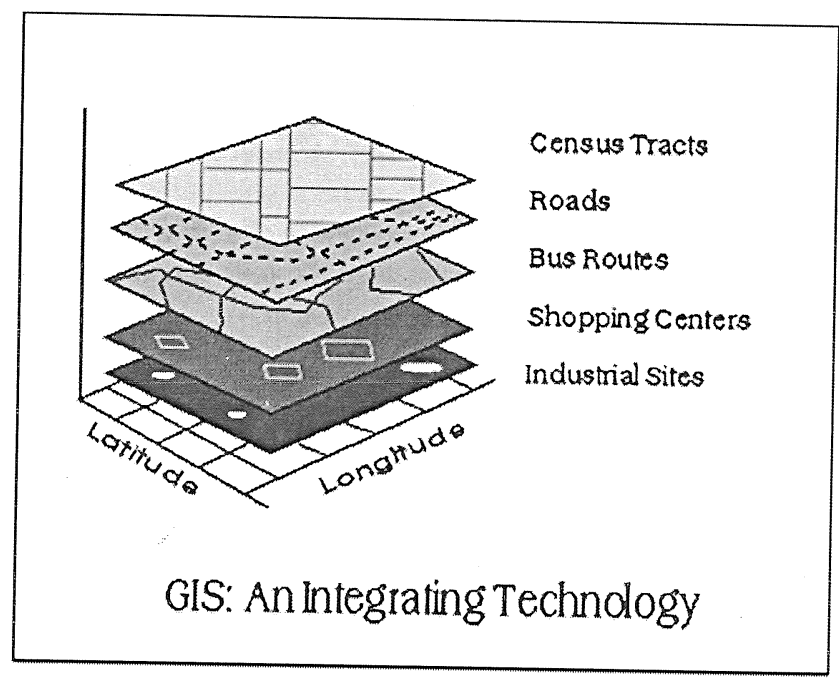

Fig. 1: Different layers in a GIS 


\section{Review of Literature}

According to a study of an American model, the success of any tourism venture is based on three factors namely Tourism planning, Tourism development and research and Tourism marketing (Fridgen, 1991). It has been established that there is a direct relationship between tourism and cartography (Arragon and Wessels, 1994). GIS could serve as a powerful tool in tourism management (Weiner, Warner \& Levin, 1996). The field of tourism has a lot to benefit from GIS because this technology has the ability to manipulate data and spatial attributes (Boyd \& Butler 1996). GIS also has the ability to identify spatial patterns in tourism sites (Mcadam, 1999). It is necessary to store, archive, select, and retrieve materials such as maps with different scales and topics, sketches with different rough calculations, paper reports and documents with various origins and structures, photographs and three dimensional landscape images. This can be accomplished using a geodatabase data model. This model brings a physical data model close to logical data model by allowing any kind of relationships to be defined among features (Zeiler, 1999). The model is displayed on a computer screen as a map or series of maps.

GIS is both a database system with specific capabilities for spatially reference data as well as a set of operations for working with the data. It may also be considered as a higher order map. GIS tools are both active and interactive and relevant to real world decision-making. These GIS tools can create complex models for analysis in which data can be turned into insightful evaluations of alternative plans and development impacts. Stakeholders can create scenarios "on the fly," and get immediate feedback on the implications of their choices, and reach consensus on outcomes more quickly (Allen \& Goers, 2002).

GIS can be used to determine the effects of the site on the surrounding environment and ecosystem, thus enabling the planner to minimize the potential negative impacts on the facility (McAdam 1999). GIS can also be employed to maximize the potential economic success of a facility by incorporating market and economic demographics into the evaluation of sites (Walford 2001). Geographic, psychographic and demographic modeling applications using GIS are abound in business and industry.

Information and communication technology (ICT) plays a key part in assisting DMOs in their operations, with important functions both in networking of local organisation and in promoting destination brand and products on the global market. The internet revolution has, obviously affected these activities strongly and DMOs have transferred much activity from traditional (mainly printed) media to the net. (Buhalis 2008) 
Geographic data in the form of mobile maps represent one cornerstone, since nearly all tourism relevant information links to a geographic location. (Hitz 2006). This is another area where applications are developed on a large scale. In order to help the tourists, digitised interactive maps have been made available over mobile networks through internet. All this will go a long way in strengthening tourist development.

\section{Study}

\subsection{Tourism and GIS}

GIS uses layers called "themes" to overlay different types of information. It is estimated that approximately $80 \%$ of all information has a "spatial" or geographic component. Therefore when making decisions about setting new facilities, creating hiking trails, protecting wetlands, directing emergency vehicles, redrawing roads maps etc, geography plays a significant role.

Planning and decision-making in tourism development is becoming increasingly complex as organizations and communities have to come in terms with the competing economic, social and environmental demands of sustainable development. Geographical Information Systems can be regarded as providing a tool box of techniques and technologies of wide applicability to the achievement of sustainable tourism development. Spatial (environmental) data can be used to explore conflicts, examine impacts and assist decision-making. Impact assessment and simulation are increasingly important in tourism development, and GIS can play a role in auditing environmental conditions, examining the suitability of locations for proposed developments, identifying conflicting interests and modeling relationships. Systematic evaluation of environmental impact is often hindered by information deficiencies but also tools for data integration, manipulation, visualization and analysis. GIS is particularly suited to this task.

In GIS maps are digitized into different layers which are sometimes called networks. A network is a set of linear features that are interconnected in GIS. Common examples of networks include highways, railways, city streets, rivers, transportation routes (eg. Transit, school buses, mail delivery etc.) and utility distribution systems (eg. Electricity, telephone, water supply and sewage). Collectively these networks form the infrastructure of modern society. Tourism industry needs voluminous data regarding tourist destinations, hotels, routes etc. These can form layers which are embedded into the map. Thus a tourist who wishes to visit a destination can get information about the destination, accommodation facilities using a GIS over the internet. This helps in reducing the intangibility associated with a tourism product. 
A person using such a system can even view the rooms in a hotel in which he plans to stay. In short GIS has found immense use in the tourism industry and will continue to play a crucial role in our lives.

Primarily there are four functions of Location Based Services for the traveler. They can be classified as Locating persons, destinations and objects, the path and interconnectivity between them, search engine for accessing information about restaurants, shops, hotels or attractions and gathering information regarding traveling conditions, weather, roads, traffic etc.

\subsection{Objectives of the proposed GIS application}

The following will be the main objectives using GIS for the future:

1. To identify the major tourist attractions using this facility. The classification of major tourist centers in Kerala based on non-spatial and attribute data will be as follows: Beaches, back waters, hill stations, wildlife sanctuaries and heritage sites. The sub-categories include Health tourism, adventure tourism and ecotourism.

2. To use maps and related information for providing a gateway for potential tourists to get a feel of the destination beforehand.

3. To help tourist plan their itinerary

4. To create a databases for future use

5. To increase overall experience of the product by reducing intangibility.

\subsection{Possible outcomes of the study}

Kerala already has a handful of departments that have harnessed the power of GIS for providing answers to various issues faced by them. By using this data, tourism department can develop an application which can be seamlessly integrated into the master plan. The major problem faced by the tourism department is the ready availability of large volumes of data. Even if the data is available, the next hurdle is how to manage and access the data in various permutations and combinations. Authentic information is fundamental to any decision making process. Therefore this has to be addressed. This demand for information and underlying data requires a new approach. The data has to be collected, stored, retrieved, analysed, communicated and presented. 
Hence an appropriate model has to be designed to perform spatial and network analysis along with manipulation of data. Most tourist impacts are spatial. This means that the impact of services and facilities are in direct proportion to its geographical proximity to other cultural and natural phenomenon. This is the primary reason why it was stated that GIS is an ideal platform for planning the future of tourism in Kerala. Tourism based GIS will facilitate the integration of all other socio-economic data, tourism work force with the database for a wide variety of planning and decision making activities. Querying is area which can be used for extracting useful information out of the system. The following are the possible query outcomes along with other useful outputs.

1. The overall view of the terrain in the state along with pointers for locating tourist spots

2. Accessibility to tourist spots and viewing the existing infrastructures

3. Type of tourist visiting the spot and their spending on various items

4. Type of economic activity centers such at food courts, bars, hotels and restaurants on a time scale

5. Transport and accommodation

6. Visualisation of tourism multiplier effect on economy.

7. Identification of hot spots

8. Identifying potential tourist destinations

9. Possible impact of new tourism related activity on the socio-economic and environmental aspects at a particular location.

10. A peek into the future for determining how tourism activity may have a negative impact in Kerala's cultural atmosphere.

\subsection{System study and development}

An up-to-date and comprehensive database has to be developed for the purpose. The smallest unit for development of the spatial database should be the panchayats which are essentially villages. Next are the municipalities and corporations. Now districts have to be incorporated which will complete the picture. The attribute data related to tourism industry must be prepared separately for each district maintaining the capabilities of its lateral integration with spatial data. Customised routines can be added to enhance the database management for processing the attribute data 
and topologically structure graphic data. Since the data in the GIS platform is tied to a common referencing system, it will be easy to use the same data across multiple queries and applications as well as to associate diverse data sets.

Given below are three screen shots from the Tour planner module from the Kerala Tourism website. Given below are three screen shots from the Tour planner module from the Kerala Tourism website.

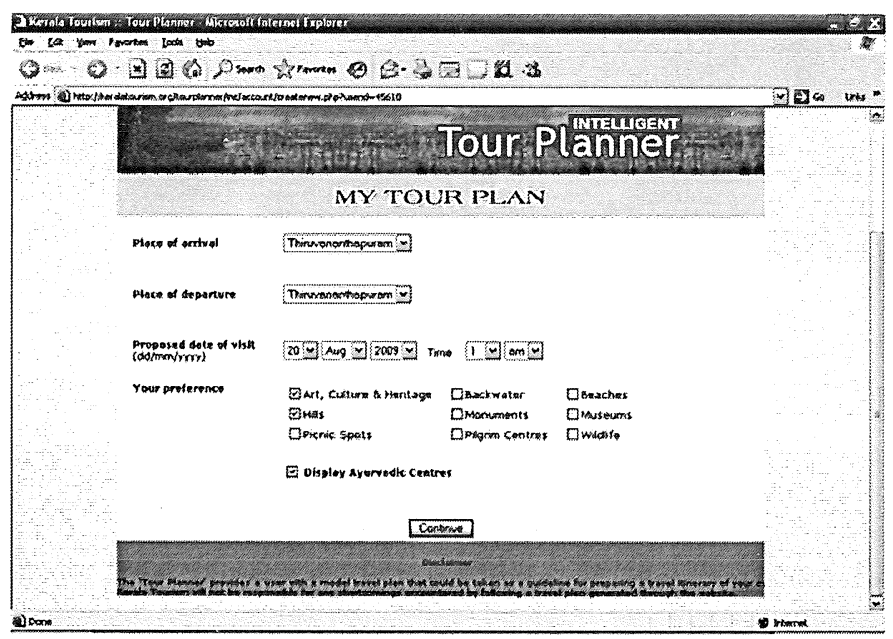

Fig. 2 Opening page of tour planner (www.keralatourism.org)

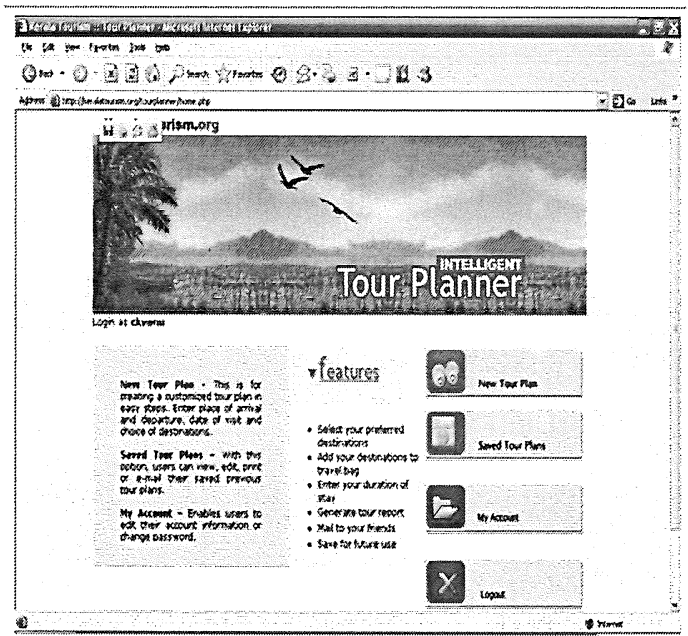

Fig. 3 Tour planner-options page (www.keralatourism.org) 


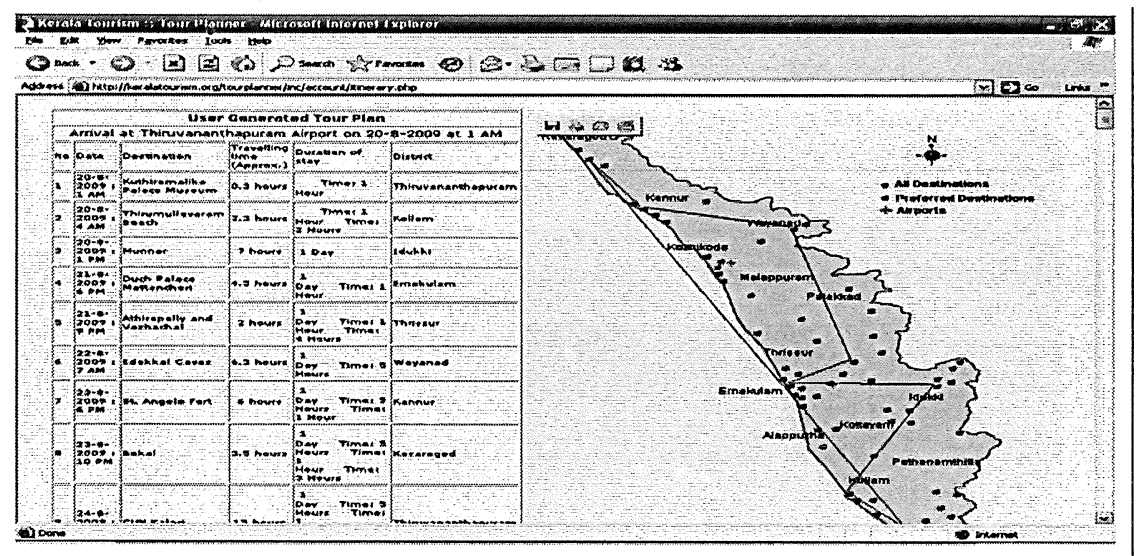

Fig. 4 Computer generated tour plan. (www.keralatourim.org)

Various search and retrieval facilities are available in this website which can be used by potential tourists to search for information. Itinerary planner and GIS map has been added to this website to enhance its utility value. The GIS map in the earlier times gave only distances between various destinations based on mouse click. But now it has been enhanced to provide various information regarding locations using layers. But still, this application has not developed into a full fledged GIS. This also gives access to online purchase of many cottage industry products such as paintings, jewelry, lamps, candles etc. They also provide services such as interior decoration customer club etc.

Even though some applications exist, it is clear that IT is not being utilized to its full potential in the Tourism sector. The present implementations have to include the integration of all sectors of tourism industry. One of the objectives of this endeavour is to integrate the elements of tourism and suggest a system to eliminate the shortcomings of the existing systems.

\section{Data Source}

To develop and execute this Tourism based GIS in Kerala, the data can be obtained from various departments such as Kerala Tourism Department, KTDC (Kerala Tourism Development Corporation), Public Works Department, Census Report from Govt. of India, Survey of India, District Panchayat Offices, State Police Department, Department of Land Records and Revenue, NGO's, Hotel associations in Kerala, Travel agents and Tour operators, Kerala State Road Transport Coporation (KSRTC), Railways, (Kerala Institute of Tourism and Travel Studies) KITTS and other secondary sources such as books, publications, magazines etc 
The development af the GIS database requires a thorough understanding of the topology and geographic peculiarities. For this a systematic and coherent implementation of GIS has to be adopted for development of an up-to-date, accessible and comprehensive database. The lowest unit for the tourism master plan for development of spatial database is the panchayat. The spatial database has to be created separately for each district using a commons standard. The attribute data related to tourism industry is to be prepared separately for each district maintaining the capabilities of its lateral integration with spatial data. Separate customized routines are required for enhancing the database management for processing the attribute data and topologically structured graphic data. Since the data at GIS platform is tied to a common referencing system, it will be advisable to use the same data across multiple queries and applications. This will help in associating diverse data sets.

A number of surveys have been conducted to find out the details regarding the infrastructure available. These may be classified under networks which the basic building blocks of a GIS. The networks will be as follows: Tourist spots (Catergory wise), Transportation layer consisting of roads, railway lines, pathways etc, sewage network consisting of collection and treatment systems, Hotels and their classification, Accommodation based on availability occupancy, rates etc, Public water supply network consisting of rural and urban networks, Scope for new lines and categorization based on the type of consumers, Power generation and consumption, Details of tour operators and travel agents, Details of Government agencies like the Department of Tourism, KTDC, DTPC's (District Tourism Promotion Councils) etc, and finallyLinking google earth to the main site of Kerala Tourism.

\section{Data Model}

When creating the GIS based data model for tourism, the information stored in our database has to be analysed. The information itself is different for each of the similar tourist destinations. For this the information has to be classified into three categories.

They are relational data, spatial information related to geography and pictures sounds, movies etc which come under the category of multimedia data.

- Relational data This consists of both numerical and textual data such as the name and address of a museum, a phone number, or the name of a road or even a house number

- Spatial data: The attribute related to geographically referenced data will have an associated geometry attribute. This attribute can be any of the three 
defined geometric types in a GIS based model. They are a point, a line, or an area.

- Multimedia based data: Mainly, the multimedia information used in any system consists of pictures, videos and sounds etc. This is the same in the proposed system also. The different entities that form our data model can be classified into the following categories:

- Territorial Structure: Kerala is a narrow strip of land sandwiched between the Arabian sea in the west and the western ghats in the east. The terrain is sloping from the east to west offering ideal drainage. Dotted with hill stations, sanctuaries and lakes Kerala is land which enthralls the visitor. With a GIS based navigational tool, these resources can be effectively tapped and made more accessible to the tourist: Tourist spots especially sanctuaries can be represented by points as is the case with towns. Districts and sanctuaries can be represented by polygons. Also links can be provided to accommodation facilities in these areas. All these can be embedded in the map to make it more meaningful and manageable.

- Network of Roads and railways: This category includes only entities of type 'Road'. There is information for the most important roads and rail network in Kerala. National highways, MC road, and other roads can be geographically represented using attributes of type 'line', without any multimedia information.

- Cultural Aspects: Cultural tourism is a major income generator for Kerala Tourism. This form of tourism includes museums, monuments and archeologically important places. The archeological survey of India (ASI) and the department of tourism, Govt. of India play a major role in determining the importance and value of such a heritage site. It would be useful to have multimedia information related to these sites. The multimedia database can include a video clip with commentary which can enrich the experience. Archeologically important destinations can be represented by points. The location of a museum or building can be represented by links from the main map and given special consideration. This would help in giving a pointer to its approximate location using the spatial data available.

- Tourism and Nafure: These are closely related entities in the sense that for tourism to thrive natural ambience is a must. The home stays, resorts, hotels etc are to be identified in this regard. Videos and pictures can be added to increase their appeal. If a commentary can be included, this will enhance the value of the product. The elements in this category can be represented by points. Places of natural beauty such as river side picnic spots, waterfails etc can be included with multimedia features. They are also by point typs attribute. 
Objects of type point, area and line can be used to represent beaches, natural spaces and rivers respectively.

- Walking tours and Heritage Routes: It will be an added advantage to have Heritage routes such as a walking tour or a guided tour with an ethnic flavour. The fort walking tour in Thiruvananthapuram is such an example. This will increase the value of the tourism product since many tourists like to find their own way through the maze. A GIS base route mapping system will provide an ideal foil for this kind of venture.

\subsection{GIS Output}

A query based model will be an ideal solution to extract the desired output from system proposed. This model can be further developed for an Interactive query based system in text, report, and graphic format. Following model is proposed for the Tourism Master Plan which will help in returning information to queries.

The terrain and locations of places in relation to tourist spots have to be chalked out. This may relate the terrain characteristics of Kerala and may help in locating the tourist spots. The routes (air, rail, road) etc can be identified related to various destinations. The accessibility to the particular spot and the available infrastructure facilities of the spot may be analyzed the problems in respect to the infrastructure can be identified. Identification of the type of tourists (domestic and foreign) visiting a place may be required and their areas of interest can be analysed. Also the

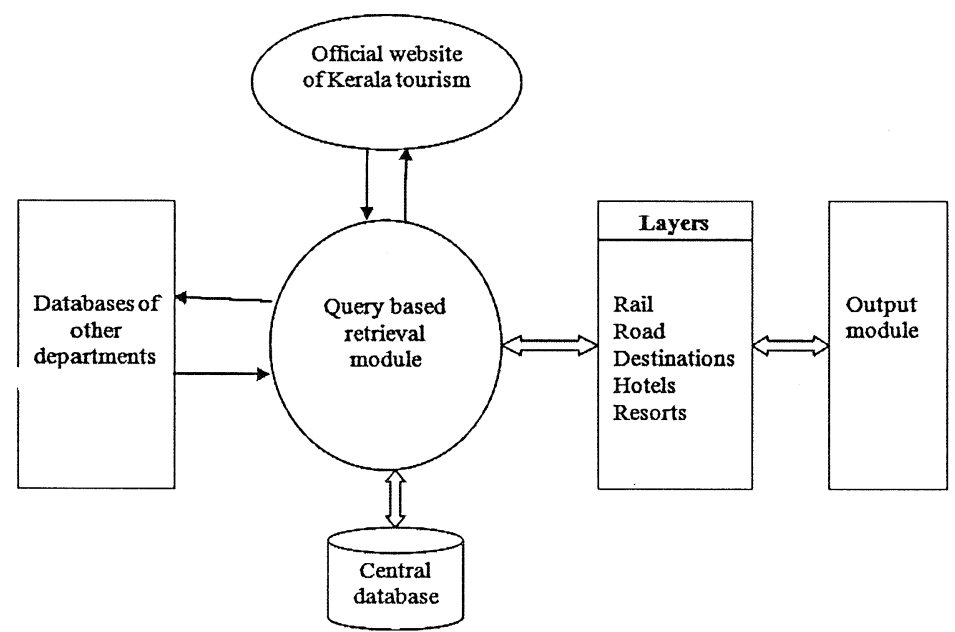

Fig. 5 A GIS based model for Kerala Tourism 
money spend on various items can be catergorised for forecusting. Type of economic activities centers such as food outlets, bars, hotel \& restaurants, on time scale. Addon services and Transport facilities can be ascertained. The multiplier effect in tourism can be further visualized and how viable a project is to the economy can be analysed. New tourist spots can be examined. Possible impact of new tourist spot/activity on socio-economic and environmental aspects at particular location etc can be examined. Vivid picture of how the tourism activity may degrade or deteriorate the existing environment of Kerala on time scale could also be generated.

\section{Conclusion}

It can be said that usage of Information Systems in Kerala is still in the developing state. Global Distribution Systems have been widely used by travel agencies with Galileo being the most widely used. By integrating these systems with the office automation systems higher efficiency can be achieved. Property Management Systems and Point Of Sale systems are used in star hotels and high class resorts. Government can take steps in providing a common platform for accessing these information systems by providing a common network. GIS has been used to a limited extent in the state but efforts are under way to tap its potential in the Tourism sector. In Kerala GIS systems are in its infancy with only minor application in Tourism websites. A concerted effort on the part of Government will help in consolidating the position of Kerala tourism in the global scenario.

Information dissemination is of utmost importance in Tourism in the Kerala scenario. If the high spending tourists are to be attracted to the state, the IT infrastructure in the state has to be further strengthened. This study aims at finding the areas where GIS has been applied in Kerala Tourism and to study its impacts. Also new thrust areas where applications need to be developed are also examined. Most of the tourists coming to Kerala, especially foreign tourist are quite knowledgeable about the various destinations and attractions. They get access to information especially over the Internet. Hence care must be taken to ensure that personnel manning the various information centers in the state are computer literate and capable of providing information. On the whole it can be conclude that a master plan for Kerala tourism based on a GIS model will provide the right impetus to Kerala Tourism. 


\section{References}

Buhalis, Dimitrios (2003) e-tourism: Information technology for strategic tourism Management. Pearson Education

Cooper, Chris; Fletcher, John; Fyall, Allan (2008) Tourism: Principles and practices. Prentice Hall Publishers, London

Egger, Roman; Buhalis, Dimitrios (2008). e-tourism case studies. Butterworth Heimann

Hitz, Martin, Sigala, Marianna, Murphy Jamie (2006) Information and communication technologies in tourism. Springerwien NY

Inkpen, Gary(1998) Information Technology for Travel and Tourism. Pitman Publishing London

McAdam D (1999) The value and scope of geographical information system in tourism management. Journal of sustainable tourism $7(1) ; 77-92$

Nag, Prithvish, Sen Guptha, Smitha (2008) Introduction to geographical information system. Concept publishing Company

O'Connor, Peter (1999) Electronic information distribution in tourism and hospitality. Cabi Publishing

Sheldon, Pauline (1997) Tourism Information Technology. Cabi Publishing

Varghese, Theresa (2006) Stark world Kerala. Stark world Publishing Ltd, TVM

Wethner, Hannes, Klein Stephan (1994) Information technology and tourism: A challenging relationship. Springerwien. NY 